\title{
Immune response to RB1-regulated senescence limits radiation-induced osteosarcoma formation
}

\author{
Maya Kansara, ${ }^{1,2}$ Huei San Leong, ${ }^{1}$ Dan Mei Lin, ${ }^{1}$ Sophie Popkiss, ${ }^{1}$ Puiyi Pang, ${ }^{1}$ \\ Dale W. Garsed, ${ }^{1}$ Carl R. Walkley, ${ }^{3}$ Carleen Cullinane,, ${ }^{1,2}$ Jason Ellul, ${ }^{1}$ Nicole M. Haynes, ${ }^{4}$ \\ Rod Hicks, ${ }^{1,2}$ Marieke L. Kuijjer, ${ }^{5}$ Anne-Marie Cleton-Jansen, ${ }^{5}$ Philip W. Hinds, ${ }^{6}$ \\ Mark J. Smyth, 1,2,4,7 and David M. Thomas ${ }^{1,2}$ \\ ${ }^{1}$ Research Division, Peter MacCallum Cancer Centre, Melbourne, Victoria, Australia. 2Sir Peter MacCallum Department of Oncology, \\ University of Melbourne, Melbourne, Victoria, Australia. ${ }^{3}$ Stem Cell Regulation Laboratory, St. Vincent's Institute, Melbourne, Victoria, Australia. \\ ${ }^{4}$ Cancer Immunology Program, Peter MacCallum Cancer Centre, Melbourne, Victoria, Australia. ${ }^{5}$ Department of Pathology, \\ Leiden University Medical Centre, Leiden, The Netherlands. ${ }^{6}$ Molecular Oncology Research Institute, Tufts Medical Center, \\ Boston, Massachusetts, USA. ${ }^{7}$ QIMR Berghofer Medical Research Institue, Brisbane, Queensland, Australia.
}

\begin{abstract}
Ionizing radiation (IR) and germline mutations in the retinoblastoma tumor suppressor gene (RB1) are the strongest risk factors for developing osteosarcoma. Recapitulating the human predisposition, we found that $R b 1^{+/-}$mice exhibited accelerated development of IR-induced osteosarcoma, with a latency of 39 weeks. Initial exposure of osteoblasts to carcinogenic doses of IR in vitro and in vivo induced RB1-dependent senescence and the expression of a panel of proteins known as senescence-associated secretory phenotype (SASP), dominated by IL-6. RB1 expression closely correlated with that of the SASP cassette in human osteosarcomas, and low expression of both RB1 and the SASP genes was associated with poor prognosis. In vivo, IL-6 was required for IR-induced senescence, which elicited NKT cell infiltration and a host inflammatory response. Mice lacking IL-6 or NKT cells had accelerated development of IR-induced osteosarcomas. These data elucidate an important link between senescence, which is a cell-autonomous tumor suppressor response, and the activation of host-dependent cancer immunosurveillance. Our findings indicate that overcoming the immune response to senescence is a rate-limiting step in the formation of IR-induced osteosarcoma.
\end{abstract}

\section{Introduction}

Both heritable and environmental factors contribute to susceptibility to osteosarcoma, the most common primary malignancy of bone (1). The retinoblastoma tumor suppressor gene (RB1) is inactivated in $20 \%$ to $40 \%$ of sporadic osteosarcomas and is linked to poor disease outcome (2). $R B 1$ was first identified as the gene mutated in human retinoblastoma (3). In survivors of childhood retinoblastoma (4), the incidence of osteosarcoma is increased > 400 fold (5) and is further increased 2 fold in patients treated with radiotherapy (6). The role of radiation as a risk factor for sarcomas is well documented (7). Sarcoma incidence increases dose dependently in patients treated with radiotherapy, and radiation-induced sarcomas are usually high grade, arise at the edge of the radiation field, show a long latency, and have a particularly poor survival (8).

RB1 is best understood as the key cell cycle checkpoint protein. Mitogenic signals activate cyclin-dependent kinases/cyclin complexes that phosphorylate RB1, releasing E2F factors that transactivate genes required for cell cycle progression (9). RB1 has been implicated in cellular differentiation, cell death, angiogenesis, metastasis, and senescence (10). In bone, RB1 regulates the differentiation and senescence of osteoblasts $(11,12)$. Emerging evidence suggests that senescence, a terminally arrested, cell-autonomous state elicited by cell aging, oncogene-induced stress, or genotoxic stress, is rate-limiting in cancer development (13). RB1 is required for oncogene-induced senescence in human

Conflict of interest: The authors have declared that no conflict of interest exists. Citation for this article: J Clin Invest. 2013;123(12):5351-5360. doi:10.1172/JCI70559. fibroblasts (14), while restoration of RB1 in osteosarcoma cell lines induces senescence $(12,15)$. Inactivation of RB1-mediated senescence mechanisms promotes tumor formation (16). Senescence is associated with expression of multiple secreted factors, including growth factors, cytokines, and proteinases, termed the SASP, whose relevance to tumor suppression is not well understood (17). The SASP appears to directly reinforce the senescent phenotype $(18,19)$, while RB1-deficient murine embryonic fibroblasts have attenuated expression of chemokines, complement, and cell surface receptors, among other genes (20).

Immune-modulated therapies have begun to have clinical impact in a number of cancer types $(21,22)$, including in sarcoma $(23,24)$. Preclinical data suggest a role for tumor-infiltrating lymphocytes in osteosarcoma $(25,26)$, while several cytokines, including IL-12, IL-2, and type I interferons, have shown preclinical activity (27-29). Adjuvant use of muramyl tripeptide phosphatidylethanolamine (mifamurtide), a synthetic lipophilic analog of a mycobacterial cell wall protein, was recently shown to improve survival of patients with osteosarcoma (30) and has been approved for clinical use. Here, we report novel mechanisms linking RB1, radiation-induced senescence, and host immune surveillance that may be relevant to radiation-induced osteosarcoma in the clinic.

\section{Results}

$\mathrm{Rb} 1^{+/-}$mice are predisposed to the development of radio-carcinogeninduced osteosarcoma. $R b 1^{+/-}$mice were used to model human $R B 1$ dependent predisposition to radiation-induced osteosarcoma. In the absence of radiation, these mice do not develop spontaneous 
A
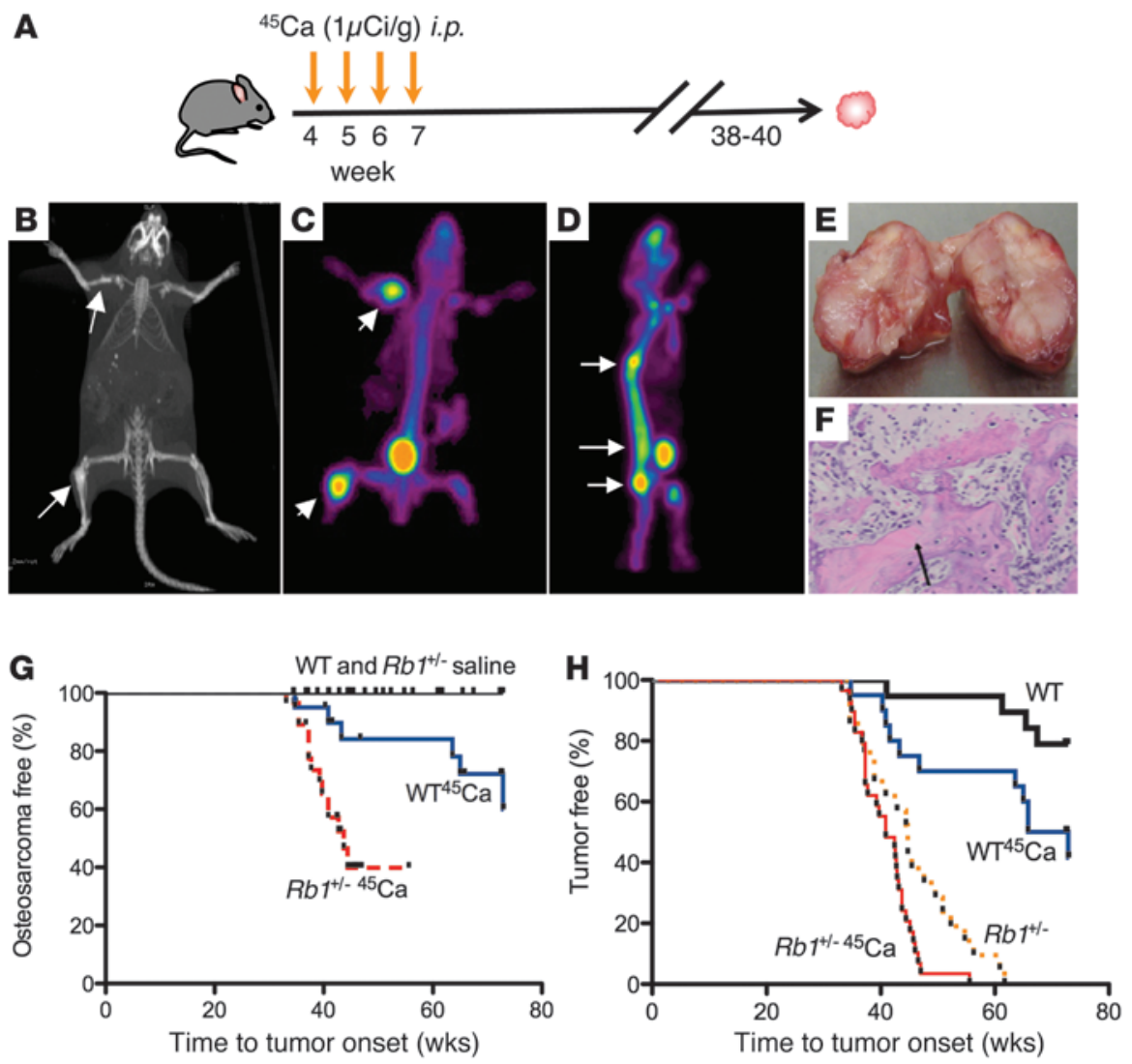

Figure 1

$R b 1^{+/-}$mice are predisposed to the development of ${ }^{45} \mathrm{Ca}$-induced osteosarcomas compared with wild-type mice. (A) Radiation-induced $\left({ }^{45} \mathrm{Ca}\right)$ mouse model of osteosarcoma. Mice at 28 days of age were injected with $1 \mu \mathrm{Ci} / \mathrm{g}{ }^{45} \mathrm{Ca}$ intraperitoneally once weekly for 4 consecutive weeks and monitored for the growth of tumors. Mice develop tumors in the spine $(70 \%)$ and limbs (18\%), and then pelvis, cranium, scapula, and clavicle $(12 \%)$, presumably reflecting distribution of isotope in vivo. (B) CT of tumors. (C and D) Micro-PET imaging using ${ }^{18 f l u o r i n e}$ of tumors. (E) Example of gross bony morphology of osteosarcoma in tibiae. (F) Microscopic examination of mouse osteosarcoma. Sections were stained with hematoxylin and eosin. Arrows point to osteoids produced by the surrounding malignant osteoblastic cells (original magnification, $\times 100$ ). Representative images are shown. (G) Cohorts of mice were injected with ${ }^{45} \mathrm{Ca}$ and monitored for tumor onset. KaplanMeier plots of osteosarcoma onset $\left(R b 1^{+/+}\right.$ saline and $R b 1^{+/+}{ }^{45} \mathrm{Ca}, n=20 ; R b 1^{+/-}$saline, $\left.n=22 ; R b 1^{+/-45} \mathrm{Ca}, n=26\right) . P=0.005, R b 1^{+/+}$ ${ }^{45} \mathrm{Ca}$ vs. $R b 1^{+/-45} \mathrm{Ca} ; P=0.007, R b 1^{+/+}$saline vs. $R b 1^{+/+}{ }^{45} \mathrm{Ca} ; P=0.0004, R b 1^{+/-}$saline vs. $R b 1^{+/-45} \mathrm{Ca}$. $(\mathbf{H})$ Kaplan-Meier plots of overall tumor onset, including osteosarcomas and pituitary and thyroid tumors (from Figure $1 \mathrm{G}$ ). $P=0.03, R b 1^{+/+}$saline vs. $R b 1^{+/-}{ }^{45} \mathrm{Ca}$; $P=0.02, R b 1^{+/-}$saline vs. $R b 1^{+/-}{ }^{45} \mathrm{Ca}$; $P<0.0001, R b 1+/+{ }^{45} \mathrm{Ca}$ vs. $R b 1+/-45 \mathrm{Ca}$; $P<0.0001, R b 1^{+/+}$saline vs. $R b 1^{+/-}$saline, Mantel-Cox log-rank test. osteosarcoma but succumb to pituitary and thyroid carcinomas by 8 months $(31,32)$. Wild-type and $R b 1^{+/-}$mice were injected with ${ }^{45} \mathrm{Ca}$, a low energy $\beta$-emitter that efficiently localizes to bone, generating osteosarcomas with $100 \%$ penetrance at 18 to 24 months after exposure to radiation (data not shown, Figure 1A, and ref. 33). To accurately assess tumor burden, fine CT (Figure 1B) and micro-PET imaging using ${ }^{18}$ fluorine of tumors were used to localize tumors (Figure 1, C and D). Morphologically and histopathologically (Figure 1, E and F), tumors recapitulated key features of human osteosarcoma, including malignant osteoblasts and tumor osteoid. Osteosarcomas in wild-type mice were detectable by 38 weeks following exposure to ${ }^{45} \mathrm{Ca}$, with a median onset at 56 weeks. The median latency of osteosarcomas in $\mathrm{Rb}^{+/-}$mice was shortened to 39 weeks ( $P=0.0009$, Mantel-Cox) (Figure 1G). All $R b 1^{+/-}$mice, regardless of exposure to ${ }^{45} \mathrm{Ca}$, demonstrated pituitary and thyroid cancers at the time of autopsy (Figure $1 \mathrm{H}$ and data not shown). As expected, $80 \%$ of $R b 1^{+/-}$osteosarcomas lacked detectable RB1 protein expression, compared with only $25 \%$ of wild-type osteosarcomas (Supplemental Figure 1; supplemental material available online with this article; doi:10.1172/JCI70559DS1).

$R B 1$-dependent cell responses to ionizing radiation in primary buman bone-derived cells. To study the role of RB1 in the radiation response in osteoblasts, primary human osteoblasts (hOBs) and shRNAs were used to knockdown RB1 expression (Figure 2A). Two independently generated stable RB1 knockdown lines were used for all subsequent experiments. Following exposure to 4 Gy ionizing radiation (IR), clonogenic survival was moderately enhanced in shRNA to RB1 (shRB1) cells compared with that in shRNA to empty vector (shEV) cells (Figure 2B), an effect associated with attenuated induction of senescence following IR. Senescence was assayed by the presence of senescence-associated $\beta$-galactosidase (SA- $\beta$-Gal; Figure $2 \mathrm{C}$ ), increased numbers of flattened cells, and expression of CDKN2A, CDKN1A, and trimethylated H3K9 (Supplemental Figure 2). Global transcriptional profiling was carried out on shRB1 and shEV hOB cell lines at $0,8,16$, and 24 hours following exposure to $4 \mathrm{~Gy}$. Using gene set enrichment analysis (GSEA) with the C2, C3, C4, and C5 sets from MSigDB database (http://www.broadinstitute.org/gsea/ msigdb/index.jsp), significant, RB1-dependent enrichment of chemokines and interferon-responsive genes was observed, reminiscent of the SASP. A cassette of previously defined SASP genes (Supplemental Table 1 and ref. 17) was upregulated in shEV cells compared with shRB1 cells (false discovery rate [FDR] $q$ value 0.0054 ), with the most differentially regulated genes, including $I l 1 b$, $I l 6$, and $I l 8$ (Figure 2D and Supplemental Table 1), cytokines shown to be critical to oncogene-induced senescence in vitro (19). The RB1-dependent induction of IL- 6 and IL-8 was verified at the protein level in shEV hOBs relative to shRB1 hOBs following IR (Figure 2E). Notably, the expression of these cytokines anticipates by several days emergence of the senescent phenotype, as assayed by SA- $\beta$-Gal at 10 days, consistent with a role in establishing senescence. 
A
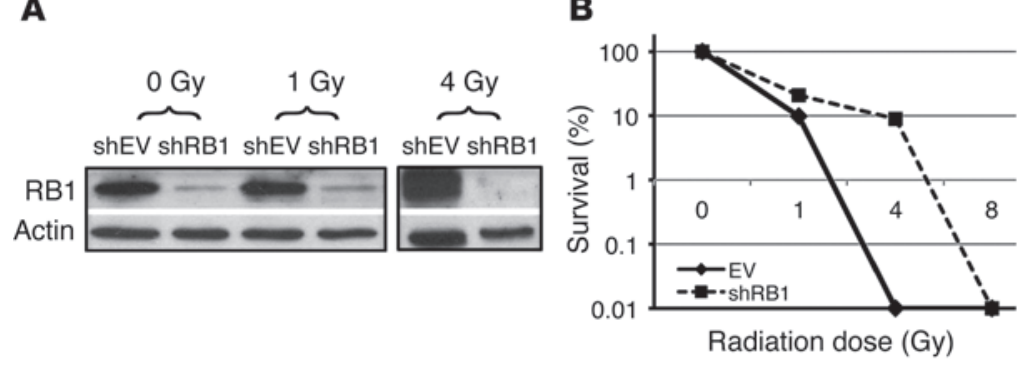

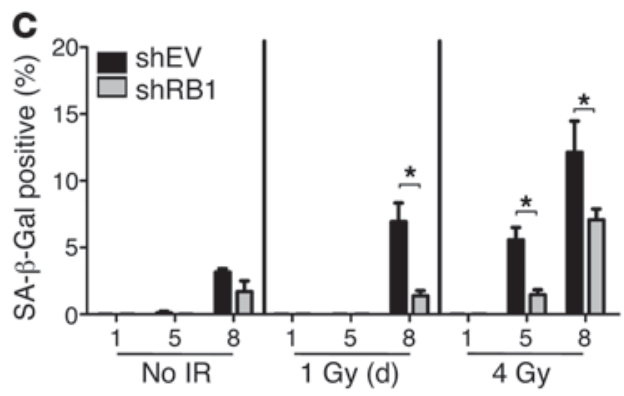

$\mathbf{E}$

Fold change IL-6 protein Fold change IL-8 protein
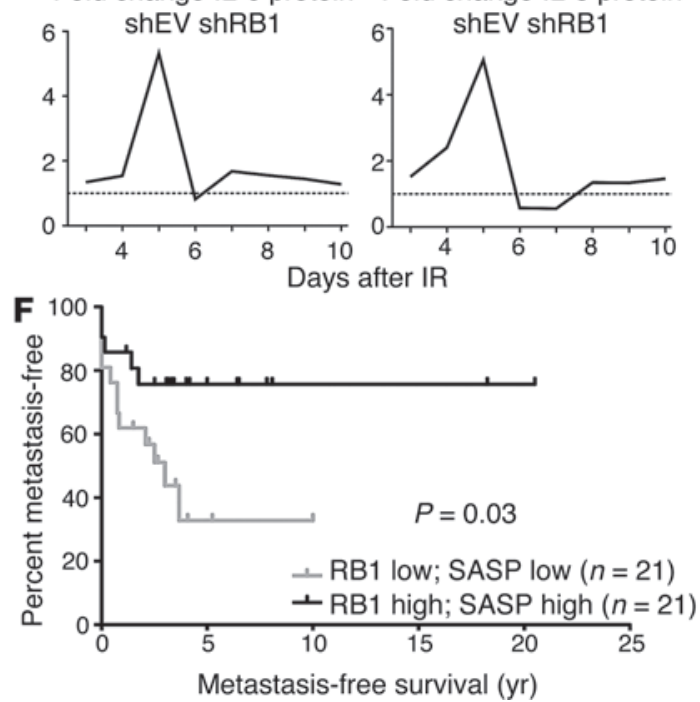

Figure 2

RNAi-mediated knockdown of RB1 attenuates senescence response following IR and reveals an immune/inflammatory signature. (A) Verification of RB1 knockdown. Western blotting was carried out using hOBs stably transfected with shRB1 or shEV at 24 hours after exposure to 0 , 1 , and 4 Gy IR. (B) Clonogenic assay for cell fitness. shEV and shRB1 knockdown cells exposed to $0,1,2,4$, and 8 Gy IR were seeded at 1,000 cells per 6-well plate, and colonies consisting of $>10$ cells were counted at days 9-11. Values represent the mean and SD of at least 3 separate experiments. (C) Quantification of SA- $\beta$-Gal staining of hOB shEV cells and hOB shRB1 cells 1, 5, and 8 days after exposure to 0 , 1, 4 Gy IR. Values represent the mean and SEM of 3 independent experiments. ${ }^{*} P$-value $<0.05,2$-tailed Student's $t$ test. (D) Global expression profiling of shEV and shRB1 hOBs $0,8,16$, and 24 hours after 4 Gy IR shows expression of differentially regulated SASP genes analyzed by GSEA. (E) IL-6 and IL-8 protein levels measured using CB bead arrays 10 days following IR. Data are expressed as fold difference between hOB shEV and hOB shRB1 in at least 3 independent experiments. (F) Effect of expression of RB1 and SASP on metastasis-free survival in primary osteosarcoma. High expression of RB1 and SASP profile was associated with better metastasis-free survival than low expression $(P=0.03$, Mantel-Cox).

To determine the relationship of RB1 and SASP expression in human tumors, a set of 84 primary human pretreatment osteosarcomas was studied. Highly significant correlations were observed between expression of RB1 and expression of IL-1 $\beta$ (Spearman $\left.r^{2}=0.46, P<0.0001\right)$, IL-6 $\left(r^{2}=0.3, P=0.005\right)$, and IL-8 $\left(r^{2}=0.42\right.$, $P<0.0001)$. Moreover, tumors with high expression of both RB1 and SASP had significantly better metastasis-free survival than tumors with low RB1 and SASP expression $(P=0.03)$, suggesting that RB1-dependent expression of SASP correlates with clinical outcomes in patients with primary osteosarcoma (Figure $2 \mathrm{~F}$ ).

$I R$ induces a senescence-associated immune response in bone in vivo. To determine the role RB1-dependent SASP response in the development of radiation-induced osteosarcoma in vivo, mice exposed to carcinogenic doses of ${ }^{45} \mathrm{Ca}$ were sacrificed at 14 days after exposure to radiation. Microscopic examination of vertebrae showed greater than 7 -fold increase in SA- $\beta$-Gal-positive cells in bone compared with that in unirradiated controls (Figure 3, A and B). Ex vivo exposure of primary calvaria to 4 Gy IR confirmed a 3-fold increase in SA- $\beta$-Gal-positive cells (data not shown) as well as induction of IL-6, CCL2 (also known as MCP-1), RANTES, MIP-1 $\alpha$, and MIP$1 \beta$ protein expression in calvarial osteoblasts (Figure 3, C and D, and Supplemental Figure 3). These data indicate that the senescent and SASP response to carcinogenic doses of IR occurs both in vitro and in vivo.

In vivo senescence-associated immune response to $I R$ is $R B 1$-dependent. To determine whether the senescence response to IR in vivo was $\mathrm{Rb} 1$ dependent, mice with conditional homozygous deletion of $R b 1$ in osteoblasts (osterix-Cre recombinase $\left(O s x-C r e^{+} ; R b 1^{f l f f l}\right.$ ) mice, referred to herein as $R b 1^{f l / f l}$ mice) and matched controls were used (34). Bone-specific excision was estimated to occur in at least $50 \%$ of osteoblasts (Supplemental Figure 4). Two weeks following exposure to a carcinogenic dose of ${ }^{45} \mathrm{Ca}$, a striking reduction in 

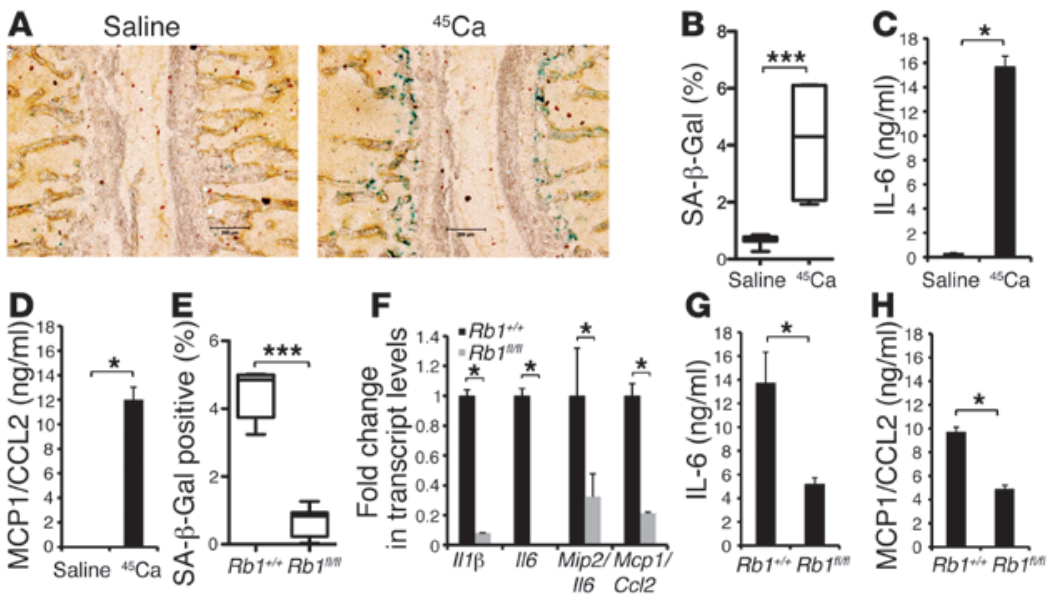

Figure 3

In vivo and ex vivo studies show differential regulation of cytokines and senescence response in bone following IR in wild-type and $R b 1^{f / f l}$ and $R b 1^{+/+}$mice. (A) C57/ Bl6 mice injected with saline or $4 \mu \mathrm{Ci}{ }^{45} \mathrm{Ca}$ were sacrificed at day 14 after injection and stained for SA- $\beta-\mathrm{Gal}$ expression. Representative image shows vertebrae with SA- $\beta$-Gal-positive cells (blue) (original magnification, $\times 100$ ). (B) SA- $\beta$-Gal staining was quantified using MetaMorph. Box-and-whisker plot shows the percentage of blue pixels in the whole image and standard error (saline vs. ${ }^{45} \mathrm{Ca}, 0.68 \pm 0.05$ vs. $4.12 \pm 1.12$, respectively; mean \pm SEM). ${ }^{* * *} P \leq 0.0001$, 2-tailed Student's $t$ test. (C and D) C57/BI6 calvarial cells were plated and exposed to IR at 4 Gy. At day 10, condition media was collected and assayed for the expression IL-6 and MCP-1 using CB bead arrays. Values shown are representative of at least 3 experiments and SEM. (E) SA- $\beta-$ Gal staining is attenuated in $R b 1^{f l / f l}$ mice compared with that in $R b 1^{+/+}$control mice. Mice were injected with $4 \mu \mathrm{Ci}{ }^{45} \mathrm{Ca}$ and sacrificed at day 14 after injection. Sections of spine were stained for SA- $\beta$-Gal. Box-and-whisker plots show mean percentage blue pixels in the whole image \pm SEM (IR $R b 1^{+/+}$vs. IR $R b 1^{\text {fllfl, }}$, mean $4.5 \pm 0.3$ vs. $0.69 \pm 0.10$, respectively; $\left.{ }^{* \star \star} P<0.0001\right)$. (F) Transcript level analysis by qRT-PCR of irradiated bone (tibiae and femurs) from $R b 1^{+/+}$and $R b 1^{f l / f l}$ mice. Values expressed relative to wild-type bone $\pm S E M$ and are representative of 3 independent experiments. ( $\mathbf{G}$ and $\mathbf{H}$ ) Expression of cytokines by $\mathrm{CB}$ bead arrays as described for $\mathbf{C}$ and $\mathbf{D}$. (C, $\mathbf{D}, \mathbf{F}$, and $\mathbf{H}){ }^{*} P<0.05$, (B and $\mathbf{E}){ }^{\star \star \star} P<0.0001,2$-tailed Student's $t$ test.

SA- $\beta$-Gal-positive staining was observed in the spines of $R b 1^{f / f l}$ mice compared with that in spines of wild-type mice (Figure $3 \mathrm{E}$ ). Consistent with a role in senescence, radiation-induced expression of $I l 1 b, I l 6, I l 8 / M i p 2$, and $M c p 1$ was markedly attenuated in $R b 1^{f / f l}$ mice relative to that in wild-type mice (Figure 3F). Confirming these findings, ex vivo studies using 4 Gy IR also showed decreased SA- $\beta$-Gal-positive staining (data not shown) and reduced protein expression of IL-6 and MCP-1 in calvaria from $R b 1^{f l / f l}$ mice compared with that in wild-type mice (Figure 3, G and H).

IL-6 expression is rate limiting for radiation-induced osteosarcoma in vivo. Although clearly RB1 dependent, it is not known whether the SASP plays a role in tumor suppression. IL-6, a pleiotropic cytokine linked to tumorigenesis, is the most differentially regulated member of the SASP response to IR. $\mathrm{Il6}^{-/-}$mice (C57/Bl6 Il6-tm1kopf/J mice) (35) exposed to carcinogenic doses of ${ }^{45} \mathrm{Ca}$ demonstrated accelerated development of osteosarcomas $(P=0.013)$ (Figure 4A). RB1 protein expression was absent in $75 \%$ of $\mathrm{Il}^{-\mathrm{C}^{-}}$osteosarcomas (Supplemental Figure 1). Early after exposure to carcinogenic doses of radiation, $\mathrm{Il}^{-\mathrm{C}^{-}}$vertebrae revealed significantly reduced staining of SA- $\beta-$ Gal-positive cells compared with wild-type vertebrae (Figure 4B), and transcript levels of $I l 1 b$ and $I l 8 /$ Mip2 were also reduced in $I l 6^{-/-}$bones (Figure $4 \mathrm{C}$ ). Taken together, these data suggest that senescence and SASP responses to IR are IL- 6 dependent and that IL- 6 is required for tumor suppression in vivo. Recently, IL- 6 was shown to play an important paracrine role in mediating oncogene-induced senescence in vitro (19). To determine whether IL-6 alone is sufficient to mediate senescence in response to radiation, control cells and shRB 1 hOBs were treated with a combination of recombinant IL- 6 and recombinant soluble IL-6 receptor (sIL-6R) as described previously $(19,36)$ or a neutralizing antibody to IL-6. Following 4 Gy of IR, IL-6 and sIL-6R restored the senescence response in shRB1 hOBs almost to that seen in wild-type cells ( $P=0.042$, 2-tailed Student's $t$ test) (Figure 4, $\mathrm{D}$ and $\mathrm{E})$. By contrast, the neutralizing antibody to IL-6 suppressed the induction of senescence following IR to baseline levels. Together, these data suggest that IL-6, acting in part by cell-autonomous mechanisms, is rate limiting for radiationinduced senescence in vitro and in vivo.

Tumors that arise in the absence of IL-6 are suppressed when transplanted into wild-type mice. IL-6 is expressed by many cell types, including $\mathrm{T}$ cells, macrophages, smooth muscle cells, and osteoblasts (37). To assess the relative contribution of host expression of IL-6, cross-transplantation experiments were performed using cell lines established from ${ }^{45} \mathrm{Ca}$-derived osteosarcomas in $\mathrm{Il6}^{-/-}$and wild-type mice. Wildtype and $\mathrm{Il6}^{-/-}$tumor cell lines (WT\#18/Il6-/-\#12) with comparable latencies were implanted in mice as shown in Figure 4F. Kaplan-Meier analysis showed highly significant tumor suppression of $\mathrm{Il6}^{-/-}$tumors implanted in wild-type mice, whereas $\mathrm{Il}^{-/-}$tumors implanted in $\mathrm{Il6^{-/- }}$ mice grew readily. Wild-type tumors grew readily in both wild-type and $I l 6^{-/-}$mice. (Figure 4, G and $\mathrm{H}$ ). This result was observed at least 4 separate times using these lines (WT\#18/Il6-/-\#12), and 2 other independently derived lines (WT\#5/Il6-/-\#13; Supplemental Figure 5). Transcript levels of Il6 in $I l 6^{-/-}$tumors transplanted into wild-type hosts were increased, consistent with host-dependent expression (Supplemental Figure 6). However, growth suppression was not associated with senescence when tumors were stained for SA- $\beta$-Gal (results not shown), and ex vivo irradiated $I l 6^{-/-}$osteosarcoma cells failed to undergo senescence by comparison with wild-type osteosarcoma cells (Supplemental Figure 7). These data, together with the data in Figure 4E, suggest that IL-6 is rate limiting for senescence, but that senescence is not required for tumor suppression in the syngenic transplant model.

To determine whether the tumor suppression was associated with an immune cell infiltrate, flow cytometric analysis was performed on $\mathrm{Il6}^{-/-}$tumors transplanted into wild-type hosts, revealing increased infiltration of $\mathrm{CD}^{+}$and $\mathrm{CD}^{+} \mathrm{T}$ cells, CD1d1restricted NKT cells, and neutrophils (Supplemental Table 2). These data collectively suggest that IL- 6 not only plays a significant cell-autonomous role in senescence, but that host-derived IL- 6 also contributes to tumor suppression.

NKT cells are rate limiting for radiation-induced osteosarcoma development in vivo. In order to determine whether host immune cells played a rate-limiting role in suppressing transplantation of $\mathrm{Il}^{-/-}$ 
A

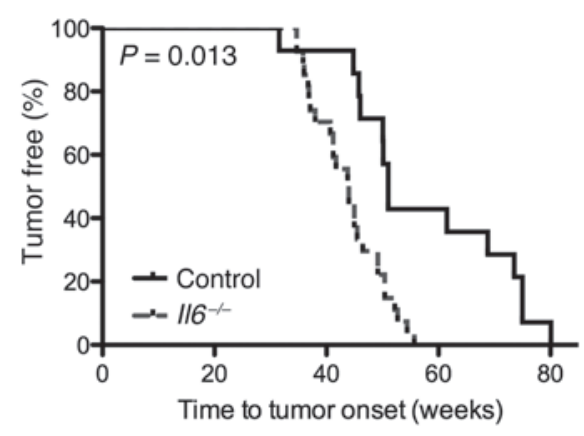

D
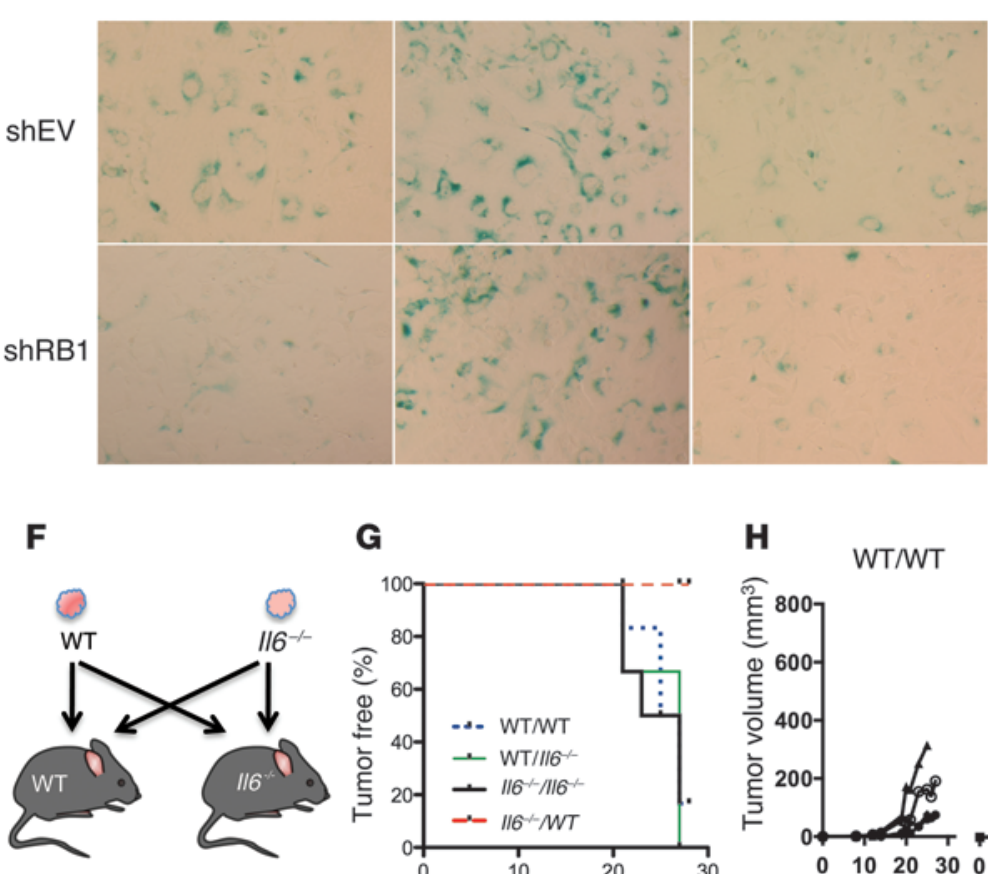

B

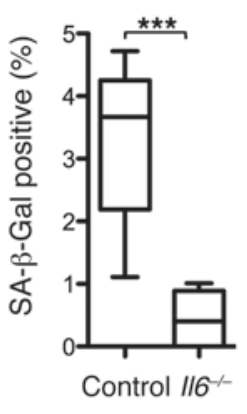

Neu IL-6
G

H

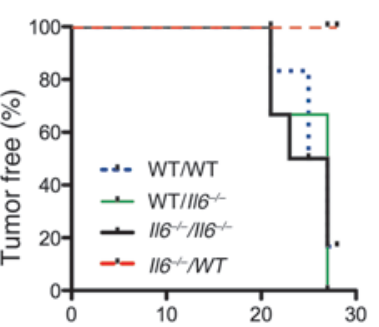

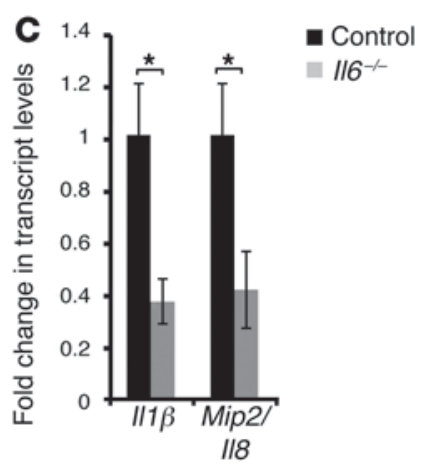

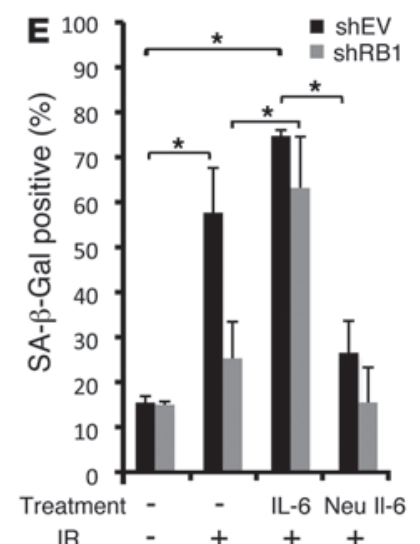

Time to tumor onset (days)

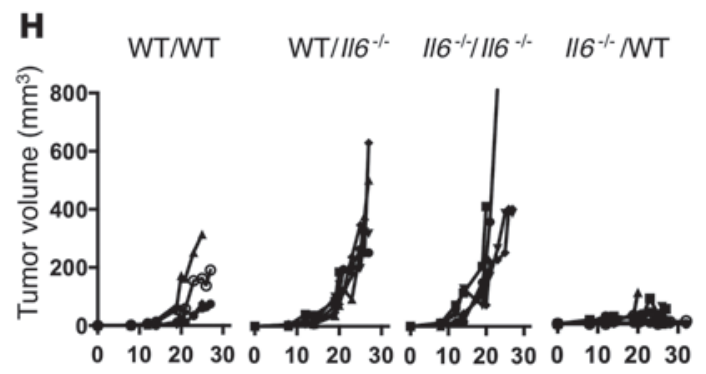

Days after cell line implantation

\section{Figure 4}

$1 / 6^{-/-}$mice are predisposed to the development of ${ }^{45} \mathrm{Ca}$-induced osteosarcomas. (A) C57/BL6 wild-type $(n=16)$ and $/ 16^{-/-}(n=27)$ mice were injected with ${ }^{45} \mathrm{Ca}$. Kaplan-Meier plots of tumor-free survival. $P=0.013$, WT vs. I/6 ${ }^{-1-}$, log-rank (Mantel-Cox) test. (B) SA- $\beta$-Gal staining in sections of spine following $4 \mu \mathrm{Ci}{ }^{45} \mathrm{Ca}$ at day 14 . Box-and-whisker plots show mean percentage blue pixels in the over whole image and SEM (IR WT vs. I/6 $6^{-1-}$, mean $3.22 \pm 0.4$ vs. $0.43 \pm 0.17$, respectively). ${ }^{* *} P<0.0001,2$-tailed Student's $t$ test. (C) Transcript level analysis by qRT-PCR of irradiated bone (tibiae and femurs) from $/ / 6^{-/}$-and wild-type mice. Expression relative to wild-type bone \pm SEM (2-tailed Student's $t$ test). Values shown are representative of 3 independent experiments. ${ }^{*} P<0.05$. (D and E) Regulation of senescence by IL-6 following IR. shEV or shRB1 hOBs were exposed to IR at 4 Gy and treated with IL-6 (hIL-6 [20 ng/ml]) and slL-6R (5 ng/ml) or neutralizing antibody to IL-6 (Neu IL-6) $(0.2 \mu \mathrm{g} / \mathrm{ml})$ for 10 days followed by SA- $\beta$-Gal staining. Original magnification, $\times 200 .{ }^{\star} P<0.05$. (F) Syngenic implantation of tumor cell lines. Wild-type and $1 / 6^{-/-}$osteosarcoma cell lines $\left(1 \times 10^{6} \mathrm{WT} \# 18 / / / 6^{-/-\# 12)}\right.$ were implanted subcutaneously into flanks of mice. (G) Kaplan-Meier survival curves. Mantel-Cox analysis for wild-type mice bearing $/ 16^{-/-}$tumors $\left(I / 6^{-1-} / \mathrm{WT}\right)$ compared to wild-type mice bearing wild-type tumors (WT/WT; $\left.P=0.009\right)$, $1 / 6^{-/-}$mice bearing $/ / 6^{-/-}$tumors $\left(I / 6^{--/} / I 6^{-/-} ; P=0.002\right)$, and wild-type mice bearing $/ / 6^{-/-}$tumors $\left(\mathrm{WT} / / / 6^{---} ; P=0.002\right)$. (H) Tumor volumes plotted for each cohort as shown from day 0 to 30 .

tumor cell lines into wild-type hosts, we repeated the experiments described in Figure 4 using mice lacking T, B, and NKT cells (Rag1/- mice). As shown in Figure 5A, the absence of lymphoid cells allowed transplantation of $I l 6^{-/-}$tumor cells, confirming that host immune cells are implicated in tumor suppression. To more specifically identify the immune cells involved in early responses to radiation in vivo, the spines of C57/B16 wild-type mice treated with carcinogenic doses of ${ }^{45} \mathrm{Ca}$ were analyzed by flow cytometry. The numbers of NKT cells, as well as NK cells and neutrophils, were markedly increased following exposure to IR (Supplemental Table 3). When the same experiment was conducted in $R b 1^{f l / f l}$ mice, NKT cell infiltration of irradiated spines was attenuated by comparison with that in wild-type mice (Figure 5B, Supplemental Table 4, and Supplemental Figure 8). 
A
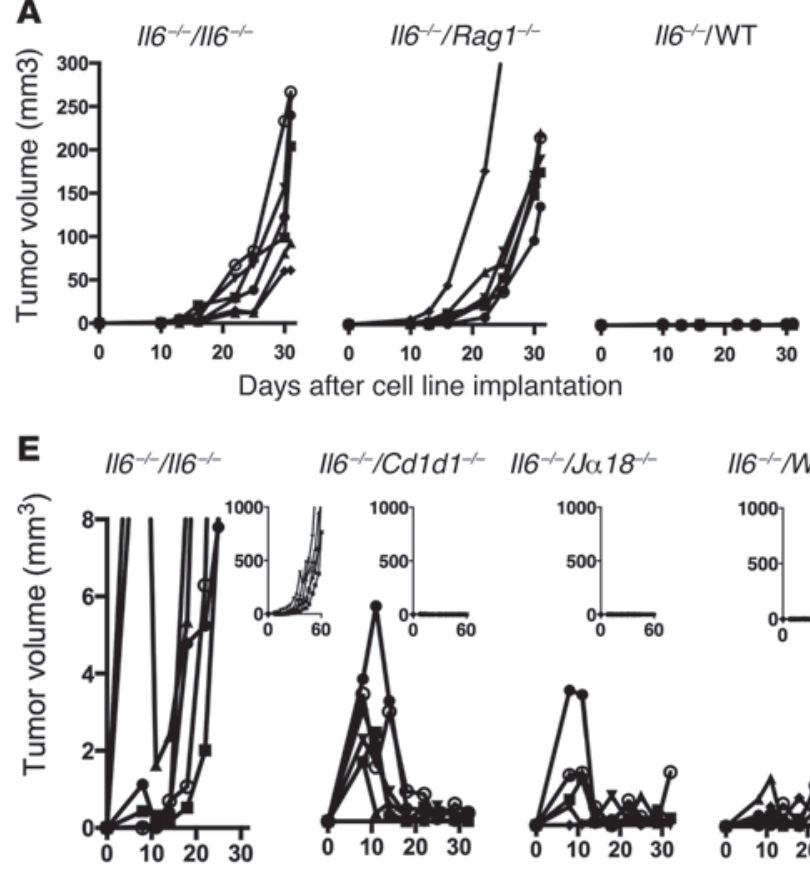
$\| 16^{--/} / C d 1 d 1^{--} \quad 116^{--/ / J} \alpha 18^{-/}$
B

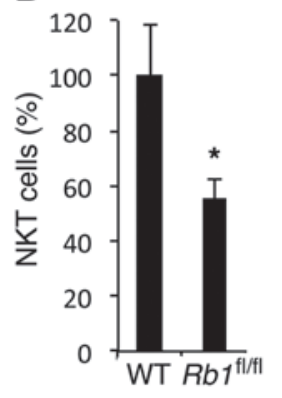

C

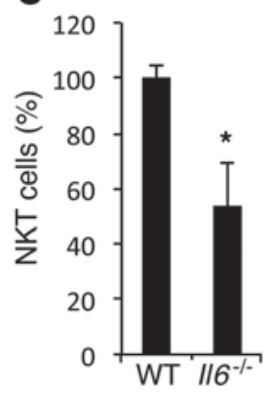

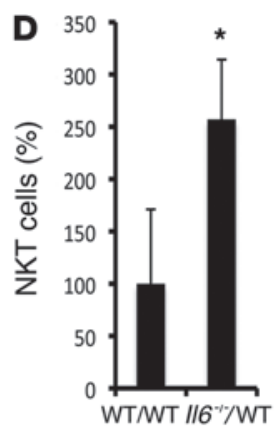

G

$\mathbf{F}$
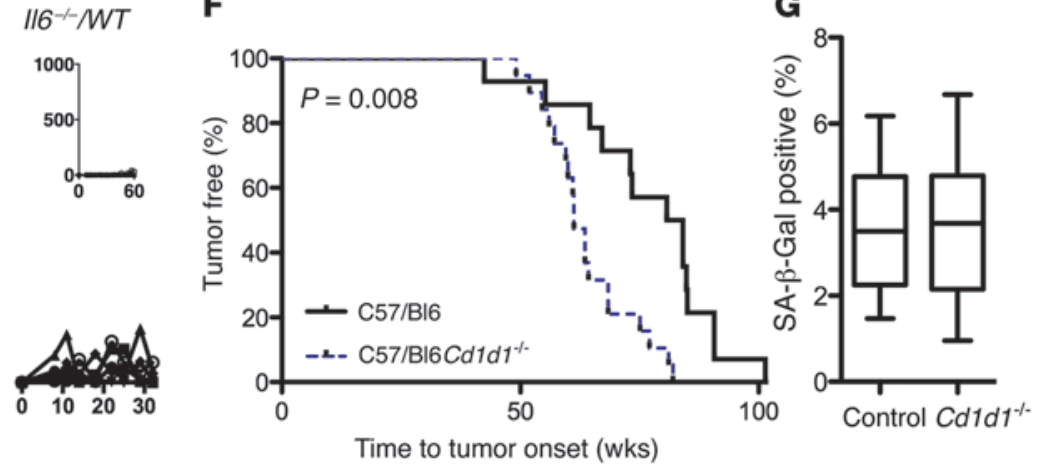

Figure 5

Cd1d1 $1^{-/-}$mice are predisposed to the development of ${ }^{45} \mathrm{Ca}$-induced osteosarcomas compared to control mice. (A) Rag $1^{-/-}$mouse background is permissive for growth of $/ / 6^{-/-}$osteosarcoma cells. The $/ / 6^{-/} \# 12$ cell line was implanted subcutaneously into the flanks of $/ / 6^{-/-}$, Rag $1^{-/-}$, and WT mice (6 per cohort), and tumor volume was measured for 30 days. (B and C) NKT cell infiltration is decreased in (B) Rb1 ${ }^{\mathrm{fllfl}}$ spines following exposure to ${ }^{45} \mathrm{Ca}$ (mean $\pm \mathrm{SEM} ; n=6-7$ per cohort; ${ }^{*} P=0.04$ compared to wild-type spines) and (C) $/ 16^{-/-}$spines 2 weeks following exposure to IR ( $n=6$ per cohort; ${ }^{*} P=0.01$ compared to WT spines). (D) NKT cell infiltration into $/ 16^{-/-}$cell lines transplanted into WT mice correlates with growth suppression ( $n=4$ per cohort; ${ }^{*} P=0.04$ compared to WT/WT). (B-D) * $P<0.05$, 2-tailed Student's $t$ test. (E) Initial growth of $I / 6^{-/-}$cell line in $\mathrm{Cd} 1 \mathrm{~d} 1^{-/-}$mice. Large graphs show immediate effect, whereas inset graphs show long-term growth. The $/ / 6^{-/-} \# 18 \mathrm{cell}$ line was implanted subcutaneously into $1 / 6^{-1-}, C d 1 d 1^{--}, J \alpha 18^{-/-}$, and WT mice, and tumor volume was measured. (F) Cohorts of C57/BL6 wild-type ( $\left.n=14\right)$ and Cd1d1 $1^{-/}(n=20)$ mice were injected with $4 \mu \mathrm{Ci} / \mathrm{g}{ }^{45} \mathrm{Ca}$. Kaplan-Meier plots of osteosarcoma onset. $P=0.008$, log-rank (Mantel-Cox) test. (G) SA- $\beta$-Gal staining in Cd1d1/-- and control mice. Mice were injected with $4 \mu \mathrm{Ci}{ }^{45} \mathrm{Ca}$ and sacrificed 2 weeks later. Sections of spine were stained for SA- $\beta$-Gal (15 images per cohort). Box-and-whisker plot shows the mean percentage blue pixels in the whole image and SEM $(P=0.4)$.

These cellular responses were specific for bone, as no differences in immune cell infiltration were observed in spleens or in spines prior to injection with ${ }^{45} \mathrm{Ca}$ (data not shown).

These data suggest that RB1 is also required for immune cell infiltration in bone following IR, particularly for NKT cells. Furthermore, $\mathrm{Il}^{-/-}$mice showed lower levels of infiltrating NKT cells in spines following IR (Figure 5C and Supplemental Table 5), and NKT cells were prominent during rejection of $\mathrm{Il6}^{-/-}$tumors transplanted into wild-type hosts (Figure 5D and Supplemental Table 3), suggesting that the SASP response is required for immune cell recruitment to irradiated bone. To investigate the role of NKT cells in tumor suppression, we implanted the $\mathrm{Il6}^{-/}$osteosarcoma cell line into mice deficient in NKT cells. Two mouse strains were used: Cd1d1 $1^{-/-}$mice (CD1d1 molecules are vital for all NKT cell development, mice lacking CD1d1 are deficient in all CD1d1-restricted NKT cells; refs. 38,39 ) and $J \alpha 18^{-/-}$mice (deficient in invariant NKT cells; ref. 40). $\mathrm{Il}^{-/-}$osteosarcoma cells initially grew more readily in $\mathrm{Cd} 1 \mathrm{d1^{-/- }}$ mice than in wild-type mice (Figure $5 \mathrm{E}$ ) but were subsequently cleared; similarly, but not to the same extent, this was also observed in J $\alpha 18^{-/-}$mice, suggesting that NKT cells play some role, but that other immune cells are also involved, in tumor clearance. To determine whether NKT cells are required for tumor suppression in vivo, $C d 1 d 1^{-/-}$mice were exposed to ${ }^{45} \mathrm{Ca}$ and shown to have accelerated development of osteosarcomas $\left(P=0.008\right.$, Mantel-Cox) (Figure 5F). However, unlike that in $\mathrm{Rb}^{+/-}$ and $I l 6^{-1-}$ mice, SA- $\beta$-Gal expression in recently irradiated bone was not significantly different in the spines of $C d 1 d 1^{-/-}$mice compared with that in control mice (Figure 5G). Taken together, these data indicate that NKT cells form part of a host tumor suppressor response to a senescence-associated alarm signal in osteoblasts exposed to carcinogenic radiation.

\section{Discussion}

IR is the single most potent environmental carcinogen in osteosarcoma and confers a particularly high risk to individuals affected by hereditary retinoblastoma $(41,42)$. The ${ }^{45}$ Ca mouse model described here recapitulates many features of human osteosarcoma. These studies provide new genetic evidence linking RB1, senescence, and host immune factors in radiation-induced osteosarcoma development (Figure 6). Senescence is well understood as a cell-autonomous process in which RB1 enforces an irreversible $\mathrm{G}_{1}$ cell cycle arrest (11). We and others $(17,43,44)$ describe a SASP that includes IL-1 $\beta$, IL-6, IL-8, and MCP-1. The SASP signature elicited by irradiation of osteoblasts is RB1 dependent, 


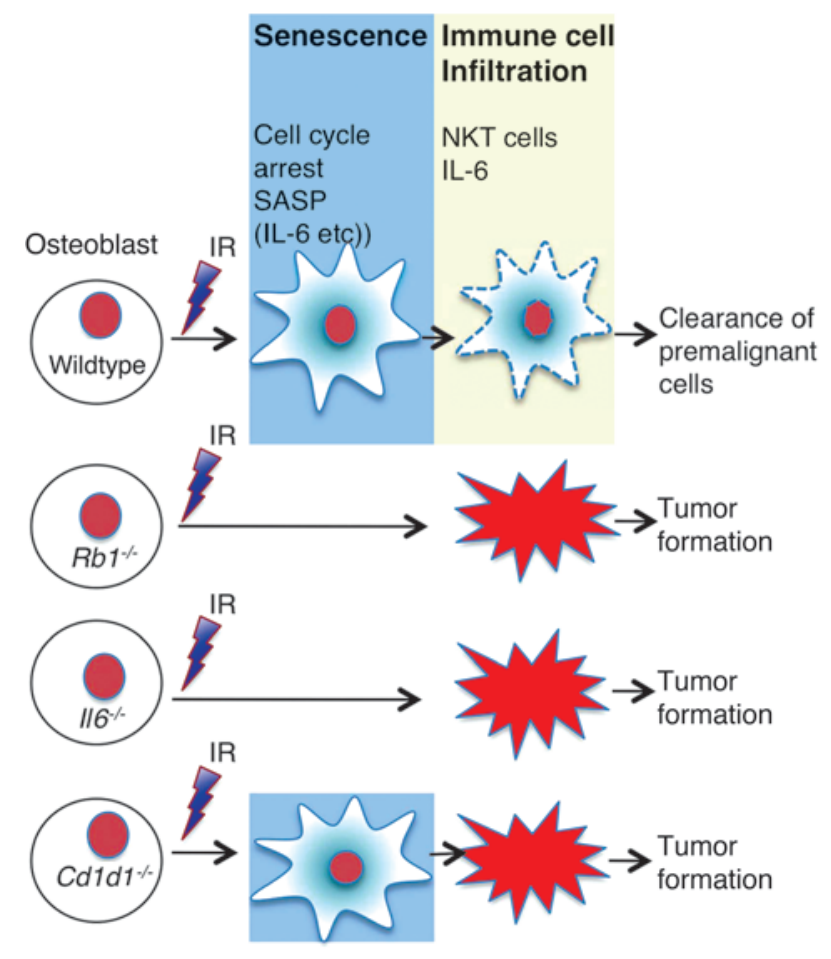

Figure 6

A model for the roles of RB1, IL-6, and NKT cells in the senescent tumor suppressor response to IR, and their deregulation in osteosarcoma. Exposure to IR activates an RB1-dependent senescence response in osteoblasts, characterized by expression of an alarm signal comprising SASP, including IL-6. Both RB1 and IL-6 (among other cytokines) contribute to senescence in a cell-autonomous fashion. Host IL-6 (and other proteins) also contributes to tumor suppression, perhaps by reinforcing the alarm signal. NKT cells (and perhaps other cellular elements of the immune system) are not required for senescence but may contribute to tumor suppression by clearance of senescent cells.

both in vitro and in vivo. IL-6, a key part of the SASP that induces senescence in vitro in a cell-autonomous fashion (19), is rate limiting for osteosarcoma development in vivo, possibly by cellautonomous and host-dependent pathways. While the mechanism behind the cell-autonomous effects of IL- 6 in particular is unknown, inflammation may play both tumor suppressor and oncogenic roles in cancer, perhaps depending on tumor type and context (45). IL-6 suppresses the growth of myeloid leukemia cell lines (46), B6 melanoma, methylcholanthrene-induced tumors, and colon adenocarcinoma $(47,48)$. Tumor suppressor mechanisms include suppression of cell growth, driving and reinforcing senescence, and alerting the immune system $(19,47)$. However, chronic inflammation and induction of NF- $\mathrm{KB}$ genes, including IL-6, play driver roles in non-Hodgkin's lymphoma and bladder cancer and multiple myeloma (49). In breast cancer, intratumoral IL-6 suppresses tumor growth, while circulating levels correlate with poor prognosis (50). Although senescence is critical in suppression of early oncogenic events, it has been suggested that expression of SASP in age-dependent senescence may actually promote cancer development (45).

SASP engage a host-dependent cellular immune response (51). Immune cell infiltration is a feature of radiation-induced tissue injury in vivo (52). In our system, RB1 appears required for the expression of SASP and infiltration of NKT cells in the bones of mice exposed to carcinogenic doses of 45Ca. The RB1-mediated stress surveillance mechanism in response to radiation may play a role in removing preneoplastic cells. Both Il-6 and Mip2 (the murine homolog of IL-8) induce neutrophil accumulation in vivo (53). MCP-1 expression by neuroblastomas is positively correlated with extent of NKT cell infiltration into tumors and patient survival (54). MIP2 is also implicated in NKT recruitment to the spleen (55). NKT cells are part of both the innate and acquired immune antitumor response (56). We show that $C d 1 d 1^{-/-}$mice, lacking NKT cells, are predisposed to ${ }^{45} \mathrm{Ca}$-induced osteosarcomas, consistent with previous findings that NKT cells play an important role in the development of sarcomas when crossed onto $\operatorname{Tr} p 53^{+/-}$mice (57). The growth inhibition of IL6-deficient cell lines in wild-type mice was accompanied by NKT cell infiltration, further supporting a role for these cells in host-dependent tumor suppression in vivo. Unlike RB1 and IL-6, senescence itself was not dependent on NKT cells, suggesting their role may be to clear senescent cells downstream of a cell-autonomous alarm signal initiated by RB1, and mediated by IL-6. Oncogene induction $\left(\mathrm{Nras}^{\mathrm{v} 12}\right.$ ) or restoration of p53 in liver cancer is also associated with cellular senescence in vivo, and tumor regression depends in part on immunologic mechanisms (51). Two caveats are important to note. First, while IL-6 and NKT cells clearly play rate-limiting roles, other cytokines and cell types undoubtedly also contribute to the overall tumor suppression. Second, there are no doubt nonredundant roles for each component, leading to gene-specific differences as well as overlapping similarities in the models described here. RB1 also regulates other tumor suppressor mechanisms (such as cell cycle regulation) that are IL-6 independent (10).

Tumor immunosurveillance has been proposed to comprise 3 phases, in which initially effective immune suppression gives way to a dynamic equilibrium and ultimately tumor escape. It appears that RB1-dependent senescence initiates an "alarm" signal, attracting the attention of the immune system. While demonstrably relevant to early stages of tumorigenesis, the cross-transplantation studies presented here suggest that IL-6, and perhaps other components of the SASP, remains critical even in transformed cell lines derived from established tumors. This view is supported by evidence in primary human osteosarcomas that the SASP not only tightly correlates with RB1 expression, but loss of expression of both RB1 and SASP genes associates with worse clinical outcomes. The dynamic nature of the immunoediting of cancers also suggests opportunities for clinical intervention. Mifamurtide, recently shown to prolong survival as an adjuvant therapy for osteosarcoma, induces expression of components of the SASP, including IL-1, IL-6, and IL-8 in patient tissues (58), while serum levels of these cytokines correlate with disease stage and progression (59). Manipulating potent cytokines is challenging due to systemic toxicities, as seen with the use of IL-2 and interferons, but a more refined understanding of the immune-mediated elimination of preneoplastic cells may offer new opportunities for intervention.

\section{Methods}

Mice. C57/B16 and C57/Bl6 Rag1 $1^{-/-}$mice were obtained from Animal Resource Centre, Perth, Australian. C57/B16 $\mathrm{Rb} 1^{+/-}$mice were provided by Patrick Humbert, and C57/Bl6 Cd1d1 $1^{-/-}$mice were provided by Mark Smyth (both at the Peter MacCallum Cancer Centre). Osx-Cre ${ }^{+} ; \mathrm{Rb}^{+/+}$ and $O s x-C r e^{+} ; R b 1^{f / f l}$ mice were provided by Carl Walkley, St. Vincent's Institute. C57/B16 Il6 ${ }^{-/-}$mice were obtained from The Walter and Eliza 
Hall Institute of Medical Research. All mice were genotyped using published protocols $(31,34,35,38-40)$. The fraction of osteoblasts in which Cre-mediated excision of $R B 1$ occurred was estimated using DNA from calvaria and tibia from $O s x$-Cre $p 53^{f / f l} p R b 1^{f / f l}$ mice; muscle was used as a control (Supplemental Figure 4).

Mouse models of osteosarcoma. For the radio-carcinogen model of osteosarcoma, mice were injected with $1 \mu \mathrm{Ci} / \mathrm{g}{ }^{45} \mathrm{Ca}$ (GE Healthcare) or $0.9 \%$ saline intraperitoneally at $28,35,42$, and 49 days postpartum (33). Mice were monitored for signs of tumorigenesis (limping, paralysis, loss of condition, poor feeding or grooming, or weight loss). Micro-PET imaging using ${ }^{18}$ fluorine of tumors and CT was used to locate osteoblastic lesions (60). When possible due to tumor site, tumors were formalin fixed for histology and snap frozen in liquid nitrogen for RNA and DNA extraction, and cells were cultured ex vivo. Short-term high dose ${ }^{45} \mathrm{Ca}$ studies used a single dose of $4 \mu \mathrm{Ci} / \mathrm{g}$ ${ }^{45} \mathrm{Ca}$ at day 28 postpartum. Mice were sacrificed 14 days after exposure to ${ }^{45} \mathrm{Ca}$, and blood, calvaria, spines, and sera were collected for analysis. Mouse calvarial cells were derived from skull caps of day 8 mice, and tissue was cut up finely and dissolved with $1 \mathrm{mg} / \mathrm{ml}$ collagenase A. In tumor transplantation studies, osteosarcoma cell lines derived from the ${ }^{45} \mathrm{Ca}$ experiments and cultured ex vivo were mixed with 50\% Matrigel (GIBCO), and a total volume of $50 \mu \mathrm{l}\left(10^{6}\right.$ cells $)$ was injected subcutaneously in the flank. Mice were monitored for tumor growth using digital calliper measurement (United Precision Machine Inc.).

hOB cultures. All procedures using human samples were reviewed and approved by the Peter MacCallum ethics committee. Primary human bone cells were derived from trabecular bone specimens obtained from patients undergoing routine hip replacement surgery, as previously described (61). RB1 was knocked down in hOBs using short hairpin microRNA (a) V2LHS 262671-1720084, (b) V2LHS130611-1720383, and (c) V2LHS130606-1720472 (Open Biosystems). A nonsilencing empty vector (EV) was used as a control. hOBs were transduced and pooled before selection with $1 \mu \mathrm{g} / \mathrm{ml}$ puromycin. Western blotting was used to verify gene knockdown, and stable cell lines were used for all experiments. For clonogenic assays, hOBs and EV and shRB1 lines were irradiated using a ${ }^{137}$ Cs source. Semiquantitative PCR was carried out using Hotstar Taq (Qiagen). Real-time PCR was carried out using SYBR Green (Applied Biosystems). GAPDH and $\beta 2 \mathrm{M}$ were used for normalization. Cell cycle responses to IR were assayed using propidium iodide (Sigma-Aldrich), and flow cytometry and cell cycle phase were quantitated using the Modfit program. SA- $\beta$-Gal was quantitated using a Senescence Cells Histochemical Staining Kit (Sigma-Aldrich). For studies investigating the role of IL-6, EV and shRB1 hOBs were seeded at 10,000 cells per 12 -well plate and irradiated at $4 \mathrm{~Gy}$. Following media change, cells were treated with human IL-6 (hIL-6; $20 \mathrm{ng} / \mathrm{ml})$ and sIL-6R $(5 \mathrm{ng} / \mathrm{ml})$ or IL-6-neutralizing antibody (goat anti-human) (PeproTech).

Transcriptional profiling. Total RNA from hOB cell lines was extracted as previously described (62). RNA from 2 independent experiments was hybridized to the Human Gene 1.0 ST array containing 28,869 genes (Affymetrix Inc.) (NCBI GEO accession GSE50532). The programs DAVID (http://david.abcc.ncifcrf.gov/) and EASE were used to generate gene ontologies. Microarray data were analyzed using GeneSpring GX 7.3.1 software (Agilent Technologies). Nonparametric ANOVA and the Benjamini and Hochberg false discovery rate correction were used to identify differentially expressed genes. Microarray data were analyzed using Broad Institute's GSEA software. The data were robust multiarray average normalized and analyzed for enrichment using the $\mathrm{C} 2, \mathrm{C} 3, \mathrm{C} 4$, and $\mathrm{C} 5$ gene sets from the MSigDB database (http://www.broadinstitute.org/gsea/ msigdb/index.jsp) and a SASP signature from Coppe et al. (17). Using gene set permutation (due to our small number of samples), any gene sets with an FDR-adjusted $P$ value of less than $5 \%$ were considered significant. Microarray data has been deposited in NCBI Gene Expression Omnibus (accession ID GSE50532).

Genome-wide gene expression data of 84 pretreatment high-grade osteosarcoma diagnostic biopsies were previously published in Kuijjer et al. (63) (PMID: 22454324, GEO accession GSE33382). Follow-up data were available for 83 out of 84 patients. Patients were divided into 4 groups based on expression of the senescence profile, which was set to average expression of the 10 senescence genes, and expression of RB1. Median expression was used as a cutoff, determining low and high expression for both parameters. Metastasis-free survival was calculated in Graphpad Prism software (version 5.01) for the group of patients with both low RB1 expression and low expression of the senescence profile $(n=21)$ and for patients with high expression of both parameters $(n=21)$. Significance was determined by the log-rank (Mantel-Cox) test.

Generation of mouse osteosarcoma cell lines. Tumors derived from the ${ }^{45} \mathrm{Ca}$ model were cut into $1-\mathrm{mm}^{3}$ pieces and cultured in alpha minimum essential media supplemented with $10 \%$ heat-inactivated fetal bovine serum (SAFC BioScience), 1\% PenStrep (Gibco), and 1\% Antibiotic-Antimycotic (100x, Gibco) in Cellstar Tissue Culture flasks (Greiner Bio-one). Cells were passaged for at least 15 to 20 passages. Cells were incubated at $37^{\circ} \mathrm{C}$ and $10 \% \mathrm{CO}_{2}$ in a humidified chamber.

Histology. Tissue was fixed in $10 \%$ neutral buffered formalin, embedded in paraffin, and sectioned and stained with hematoxylin and eosin. Slides were scanned on Scan Score XT (Aperio). Staining for senescence was carried out using the Senescence Cell Histological Staining Kit (Sigma-Aldrich). For the short-term high-dose ${ }^{45} \mathrm{Ca}$ studies, spines were excised and fresh frozen in OCT, and $20-\mu \mathrm{M}$ sections were cut onto plastic tape using the CryoJane-ECU microtome (Instrumedics). Images were taken on Olympus BX-51 using the $\times 10$ optic, and the percentage of SA- $\beta$-Gal staining was determined using Metamorph. The percentage positive pixels within each image was quantitated with the help of the Microscopy/Histology core at Peter MacCallum Cancer Centre. Box-and-whisker plots show the percentage of blue pixels in images.

Western blot analysis. hOBs were irradiated at $4 \mathrm{~Gy}$, and protein samples were collected at $0,2,4,8,16$, and 24 hours after irradiation. Western blots were carried out using whole cell extracts resolved on $7 \%$ and $12 \%$ SDSPAGE gels. Proteins were transferred onto Immobilon membrane (Millipore) using a Bio-Rad Semi-Dry Transfer Cell. Blots were probed with antibodies against RB1 (Oncogene) and $\beta$-actin (Sigma-Aldrich), RB1 (C-15; Santa Cruz Biotechnology), p16INK4A (EP435Y; Epitomics), p21CIP1 (cl12d1; Cell Signaling), anti-Histone H3 (H3K9) (ab8898; Abcam), Gapdh (6C5; Abcam), and actin (Ac74; Sigma-Aldrich). Proteins were detected using the Enhanced Chemiluminescence Kit (Amersham Bioscience).

Gene expression analysis and statistical methods. Tibiae and femurs were flushed of bone marrow and crushed using metal lysis beads (MP Biochemicals). All mRNA analysis was performed using quantitative PCR as previously described (64). Statistical analysis was performed using GraphPad Prism software. Primers sequences are as follows: Il1b (5'-GGTCAAAGGTTTGGAAGCAG-3', 5'-TGTGAAATGCCACCTTTTGA-3') Il6 (5'-ACCAGAGGAAATTTTCAATAGGC-3', 5'-TGATGCACTTGCAGAAAACA-3'), Mip2/Cxcl2 (5'-TCCAGGTCAGTTAGCCTTGC-3'， 5'-CGGTCAAAAAGTTTGCCTTG-3'), Mcp1 (5'-ATTGGGATCATCTTGCTGGT-3', 5'-CCTGCTGTTCACAGTTG CC-3'), Rps27a (5'-TCCTGGATCTTGGCCTTTAC-3', 5'-CCACGATGCAGATCTTTGTG-3'), Actb (5'-ATGGAGGGGAATACAGCCC-3', 5'-TTCTTTGCAGCTCCTTCGTT-3').

Immune cell infiltration analysis. Spines and tumors were washed in PBS, cut into $1-\mathrm{mm}^{3}$ pieces, and tissue digested in DMEM supplemented with $2 \%$ FCS and $10 \mathrm{mg} / \mathrm{ml}$ collagenase A for 45 minutes at $37^{\circ} \mathrm{C}$. Cells were passed through a $40-\mu \mathrm{m}$ cellular sieve and analyzed immediately after 
incubation with antibodies. Murine splenocytes were used as positive controls for immune cells. Cells were analyzed using the LSR II FACS system (BD Biosciences) and BD Diva software. Data generated were analyzed using GateLogic software. Antibodies were purchased from either eBioscience (anti-TCR $\beta$ [H57-597], anti-CD4 [L3T4], anti-CD8 [53-6.7], antiNK1.1 [PK136], anti-CD45.2 [clone 104], anti-CD19 [D3], anti-CD11c [N418], anti-CD11b [M1/70], anti-F480 [BM8], and anti-Ly6G [RB6-8C5]) or BD Biosciences (anti-MHC II [SF1-1.1] and anti-Gr1 [AL-21]). The NKT tetramer (anti-TCRint CD1d- $\alpha$-GalCer) was a gift from Dale I. Godfrey (Department of Microbiology and Immunology, University of Melbourne).

Statistics. Values are reported as mean \pm SEM. When comparing 2 groups, $P$ values were calculated using 2 -tailed Student's $t$ tests. For time-to-event and survival analysis, $P$ values for the Kaplan-Meier survival curves were calculated with a log-rank Mantel-Cox test. Significance was conventionally accepted at $P$ values equal to or less than 0.05 .

Study approval. All procedures using mice were reviewed and approved by the Peter MacCallum animal ethics experimentation committee.

\section{Acknowledgments}

This work was supported by grants from the Sarcoma Foundation of America; the National Health and Medical Research Council (NHMRC); Intramural Research Program of the Eunice Kennedy Shriver National Institute of Child Health and Human Development, NIH; and the Victorian Cancer Agency. D.M. Thomas was supported by a NHMRC Senior Research Fellowship, and M.J. Smyth was supported by a NHMRC Australia Fellowship.

Received for publication April 22, 2013, and accepted in revised form September 5, 2013.

Address correspondence to: David M. Thomas, Sarcoma Genomics and Genetics Laboratory, Research Division, Peter MacCallum Cancer Centre, St. Andrews Place, East Melbourne 3002, Victoria, Australia. Phone: 613.9656.1111; Fax: 613.9656.5208; E-mail david.thomas@petermac.org.
1. Kansara M, Thomas DM. Molecular pathogenesis of osteosarcoma. DNA Cell Biol. 2007;26(1):1-18.

2. Toguchida J, et al. Preferential mutation of paternally derived RB gene as the initial event in sporadic osteosarcoma. Nature. 1989;338(6211):156-158.

3. Lee WH, Bookstein R, Hong F, Young LJ, Shew JY, Lee EY. Human retinoblastoma susceptibility gene: cloning, identification, and sequence. Science. 1987; 235(4794):1394-1399.

4. Gurney JG, Severson RK, Davis S, Robison LL. Incidence of cancer in children in the United States. Sex-, race-, and 1-year age-specific rates by histologic type. Cancer. 1995;75(8):2186-2195.

5. Hansen MF, Cavenee WK. Retinoblastoma and osteosarcoma: the prototypic cancer family. Acta PaediatrJpn. 1987;29(4):526-533.

6. Eng C, et al. Mortality from second tumors among long-term survivors of retinoblastoma. J Natl Cancer Inst. 1993;85(14):1121-1128.

7. Huvos AG, Woodard HQ. Postradiation sarcomas of bone. Health Phys. 1988;55(4):631-636.

8. Virtanen A, Pukkala E, Auvinen A. Incidence of bone and soft tissue sarcoma after radiotherapy: a cohort study of 295,712 Finnish cancer patients. Int J Cancer. 2006;118(4):1017-1021.

9. Hiebert SW, Chellappan SP, Horowitz JM, Nevins JR. The interaction of RB with E2F coincides with an inhibition of the transcriptional activity of E2F. Genes Dev. 1992;6(2):177-185.

10. Burkhart DL, Sage J. Cellular mechanisms of tumour suppression by the retinoblastoma gene. Nat Rev Cancer. 2008;8(9):671-682.

11. Alexander K, Hinds PW. Requirement for $\mathrm{p} 27(\mathrm{KIP} 1)$ in retinoblastoma protein-mediated senescence. Mol Cell Biol. 2001;21(11):3616-3631.

12. Thomas DM, et al. The retinoblastoma protein acts as a transcriptional coactivator required for osteogenic differentiation. Mol Cell. 2001;8(2):303-316.

13. Campisi J, d'Adda di Fagagna F. Cellular senescence: when bad things happen to good cells. Nat Rev Mol Cell Biol. 2007;8(9):729-740.

14. Serrano M, Lin AW, McCurrach ME, Beach D, Lowe SW. Oncogenic ras provokes premature cell senescence associated with accumulation of p53 and p16INK4a. Cell. 1997;88(5):593-602.

15. Tiemann F, Hinds PW. Induction of DNA synthesis and apoptosis by regulated inactivation of a temperature-sensitive retinoblastoma protein. EMBOJ. 1998; 17(4):1040-1052.

16. Chow LM, et al. Cooperativity within and among Pten, p53, and Rb pathways induces high-grade astrocytoma in adult brain. Cancer Cell. 2011; 19(3):305-316.

17. Coppe JP, et al. Senescence-associated secretory phenotypes reveal cell-nonautonomous functions of oncogenic RAS and the p53 tumor suppressor. PLoS Biol. 2008;6(12):2853-2868.

18. Acosta JC, O'Loghlen A, Banito A, Raguz S, Gil J. Control of senescence by CXCR2 and its ligands. Cell Cycle. 2008;7(19):2956-2959.

19. Kuilman T, et al. Oncogene-induced senescence relayed by an interleukin-dependent inflammatory network. Cell. 2008;133(6):1019-1031.

20. Markey MP, et al. Loss of the retinoblastoma tumor suppressor: differential action on transcriptional programs related to cell cycle control and immune function. Oncogene. 2007;26(43):6307-6318.

21. Hodi FS, et al. Improved survival with ipilimumab in patients with metastatic melanoma. $N$ Engl J Med. 2010;363(8):711-723.

22. Brahmer JR, et al. Safety and activity of anti-PD-L1 antibody in patients with advanced cancer. $N$ EnglJ Med. 2012;366(26):2455-2465.

23. Schreiber RD, Old LJ, Smyth MJ. Cancer immunoediting: integrating immunity's roles in cancer suppression and promotion. Science. 2011; 331(6024):1565-1570.

24. DuPage M, Mazumdar C, Schmidt LM, Cheung AF, Jacks T. Expression of tumour-specific antigens underlies cancer immunoediting. Nature. 2012; 482(7385):405-409.

25. Theoleyre S, et al. Phenotypic and functional analysis of lymphocytes infiltrating osteolytic tumors: use as a possible therapeutic approach of osteosarcoma. BMC Cancer. 2005;5:123.

26. Biller BJ, Guth A, Burton JH, Dow SW. Decreased ratio of CD8+ T cells to regulatory $\mathrm{T}$ cells associated with decreased survival in dogs with osteosarcoma. J Vet Intern Med. 2010;24(5):1118-1123.

27. Zhou Z, Lafleur EA, Koshkina NV, Worth LL, Lester MS, Kleinerman ES. Interleukin-12 up-regulates Fas expression in human osteosarcoma and Ewing's sarcoma cells by enhancing its promoter activity. Mol Cancer Res. 2005;3(12):685-691.

28. Schwinger W, et al. Feasibility of high-dose interleukin-2 in heavily pretreated pediatric cancer patients. Ann Oncol. 2005;16(7):1199-1206.

29. Strander $\mathrm{H}$, et al. Adjuvant interferon treatment of human osteosarcoma. Recent Results Cancer Res. 1982; 80:103-107.

30. Meyers PA, et al. Osteosarcoma: the addition of muramyl tripeptide to chemotherapy improves overall survival - a report from the Children's Oncology Group. J Clin Oncol. 2008;26(4):633-638.

31. Clarke AR. Murine models of neoplasia: functional analysis of the - suppressor genes Rb-1 and p53. Cancer Metastasis Rev. 1995;14(2):125-148.

32. Jacks T, Fazeli A, Schmitt EM, Bronson RT, Goodell MA, Weinberg RA. Effects of an Rb mutation in the mouse. Nature. 1992;359(6393):295-300.
33. Finkel MP, Jinkins P B, Biskis BO. Parameters of radiation dosage that influence production of osteogenic sarcomas in mice. Natl Cancer Inst Monogr. 1964;14:243-269.

34. Walkley CR, et al. Conditional mouse osteosarcoma, dependent on p53 loss and potentiated by loss of Rb, mimics the human disease. Genes Dev. 2008; 22(12):1662-1676.

35. Kopf M, et al. Impaired immune and acute-phase responses in interleukin-6-deficient mice. Nature. 1994;368(6469):339-342.

36. Rose-John S. IL- 6 trans-signaling via the soluble IL-6 receptor: importance for the pro-inflammatory activities of IL-6. Int J Biol Sci. 2012; 8(9):1237-1247.

37. Feyen JH, Elford P, Di Padova FE, Trechsel U. Interleukin- 6 is produced by bone and modulated by parathyroid hormone. J Bone Miner Res. 1989; 4(4):633-638.

38. Hong $S$, et al. Lipid antigen presentation in the immune system: lessons learned from CD1d knockout mice. Immunol Rev. 1999;169:31-44.

39. Mendiratta SK MW. CD1d1 mutant mice are deficient in natural $\mathrm{T}$ cells that promptly produce IL-4. Immunity. 1997;6(4):469-477.

40. Cui J ST, Koseki H KM. Requirement for V a 14 NKT cells in IL-12-mediated rejection of tumors. Science. 1997;278(5343):1623.

41. Chan LL, Czerniak BA, Ginsberg LE. Radiationinduced osteosarcoma after bilateral childhood retinoblastoma. AJR Am J Roentgenol. 2000; 174(5):1288.

42. Chauveinc L, et al. Osteosarcoma following retinoblastoma: age at onset and latency period. Ophthalmic Genet. 2001;22(2):77-88.

43. Davalos AR, Coppe JP, Campisi J, Desprez PY. Senescent cells as a source of inflammatory factors for tumor progression. Cancer Metastasis Rev. 2010; 29(2):273-283.

44. Muller K, Meineke V. Radiation-induced alterations in cytokine production by skin cells. Exp Hematol. 2007;35(4 suppl 1):96-104.

45. Rodier F, Campisi J. Four faces of cellular senescence. J Cell Biol. 2011;192(4):547-556.

46. Givon T, Slavin S, Haran-Ghera N, Michalevicz R, Revel M. Antitumor effects of human recombinant interleukin- 6 on acute myeloid leukemia in mice and in cell cultures. Blood. 1992;79(9):2392-2398.

47. Revel M, et al. Interleukin-6: effects on tumor models in mice and on the cellular regulation of transcription factor IRF-1. Ann N Y Acad Sci. 1995; 762:342-355

48. Katz A, Sulman LM, Porgador A, Revel M, Feldman M, Eisenbach L. Abrogation of B16 melanoma metastasis by long term dose of interleukin- 6 ther- 
apy. J Immunother Emphasis Tumor Immunol. 1993; 13(2):98-109.

49. Aggarwal BB, Shishodia S, Sandur SK, Pandey MK, Sethi G. Inflammation and cancer: how hot is the link? Biochem Pharmacol. 2007;72(11):1605-1621.

50. Dethlefsen C, Højfeldt G, Hojman P. The role of intratumoral and systemic IL- 6 in breast cancer. Breast Cancer Res Treat. 2013;138(3):657-664.

51. Kang TW, et al. Senescence surveillance of premalignant hepatocytes limits liver cancer development. Nature. 2011;479(7374):547-551.

52. di Carlo E, et al. Neutrophils in anti-cancer immunological strategies: old players in new games. J Hematother Stem Cell Res. 2001;10(6):739-748.

53. Fielding CA, et al. IL- 6 regulates neutrophil trafficking during acute inflammation via STAT3. J Immunol. 2008;181(3):2189-2195.

54. Metelitsa LS, et al. Natural killer T cells infiltrate neuroblastomas expressing the chemokine CCL2. J Exp Med. 2004;199(9):1213-1221.
55. Faunce DE, Sonoda K-H, Stein-Sreilein J. MIP2 recruits NKT cells to spleen during tolerance induction. J Immunol. 2001;166(1):313-321.

56. Terabe M, Berzofsky JA. The role of NKT cells in tumor immunity. Adv Cancer Res. 2008;101:277-348.

57. Swann JB, et al. Type I natural killer T cells suppress tumors caused by p53 loss in mice. Blood. 2009; 113(25):6382-6385

58. Asano T, McWatters A, An T, Matsushima K, Kleinerman ES. Liposomal muramyl tripeptide up-regulates interleukin-1 alpha, interleukin-1 beta, tumor necrosis factor-alpha, interleukin- 6 and interleukin-8 gene expression in human monocytes. J Pharmacol Exp Ther. 1994; 268(2):1032-1039.

59. Rutkowski P, Kaminska J, Kowalska M, Ruka W, Steffen J. Cytokine and cytokine receptor serum levels in adult bone sarcoma patients: correlations with local tumor extent and prognosis. J Surg Oncol. 2003; 84(3):151-159.
60. Cullinane $\mathrm{C}$, et al. An in vivo tumor model exploiting metabolic response as a biomarker for targeted drug development. Cancer Res. 2005;65(21):9633-9636.

61. Gronthos S, Zannettino ACW, Graves SE, Ohta S, Hay SJ. Differential cell surface expression of the STRO-1 and alkaline phosphatase antigens on discrete developmental stages in primary cultures of human bone cells. J Bone Miner Res. 1999;14(1):47-56.

62. Morgan T, et al. Molecular profiling of giant cell tumor of bone and the osteoclastic localization of ligand for receptor activator of nuclear factor kappaB. Am J Pathol. 2005;167(1):117-128.

63. Kuijjer ML, et al. Identification of osteosarcoma driver genes by integrative analysis of copy number and gene expression data. Genes Chromosomes Cancer. 2012;51(7):696-706

64. Kansara M, et al. Wnt inhibitory factor 1 is epigenetically silenced in human osteosarcoma, and targeted disruption accelerates osteosarcomagenesis in mice. J Clin Invest. 2009;119(4):837-851. 